\title{
Transdiagnostic Evaluation Protocol for Stress, Anxiety and Depression: An Analysis with Colombian Victims
}

\author{
Bertha Lucía Avendaño-Prieto ${ }^{1}$ \\ Orcid.org/0000-0002-8136-5380 \\ Ronald Alberto Toro-Tobar ${ }^{*}, 1$ \\ Orcid.org/0000-0001-6061-3499 \\ Nancy Marina Vargas-Espinosa ${ }^{1}$ \\ Orcid.org/0000-0001- 9492-9176 \\ Javier Villalba-Garzón ${ }^{2}$ \\ Orcid.org/0000-0002-5358-2353
}

${ }^{1}$ Universidad Católica de Colombia, Bogotá, Colombia

${ }^{2}$ Universidad Nacional de Colombia, Bogotá, Colombia

\begin{abstract}
Two studies were undertaken following the transdiagnostic model, an evaluation protocol for stress, anxiety, and depression was designed. The first one was instrumental, in which the validity of the content of the protocol was established through interjudged harmony judgment, with nine experts in transdiagnostic evaluation, who evaluated the general aspects, the transdiagnostic variables included, the clinical problems, and the instruments proposed, using the modified Angoff technique. The $r_{\text {wg }}$ coefficients fluctuated between .33 and .97 showing inter-judge agreement. The indicators of severity and indulgence allowed us to infer that the evaluation of the experts was favorable. In the second study, the average scores obtained in the application of the protocol were compared to 15 victims of the armed conflict and 73 symptomatic people. There were no statistically significant differences between the means of the transdiagnostic variables between the two groups, $p$-values fluctuated between .09 and .95 , this results allow us to infer that anxiety sensitivity, intolerance to uncertainty and positive-negative affect as transdiagnostic variables can be identified by means of the protocol regardless of the type of diagnosis or condition of victim.
\end{abstract}

Keywords: Stress, anxiety, depression, transdiagnosis, protocol.

* Mailing address: Avenida Caracas \# 46 - 22, Bogotá, Colombia. E-mail: blavendano@ucatolica.edu.co, ratoro@ucatolica.edu.co,nmvargas@ucatolica.edu.co and javierandresvillalba@gmail.com

Documento derivado del proyecto de investigación institucional titulado: Diseño de un protocolo de evaluación transdiagnóstica para víctimas y no víctimas del conflicto (4110016).

Acknowledgments: The authors thank the Catholic University of Colombia for its financial support in the conduct of this research. 


\section{Protocolo de Avaliação Transdiagnóstica para o Estresse, Ansiedade e Depressão: Uma Análise com as Vítimas Colombianas}

\section{Resumo}

O objetivo deste estudo foi descrever as propriedades de um protocolo para a avaliação do estresse, a ansiedade e a depressão, elaborado segundo o modelo transdiagnóstico. Realizaram-se dois estudos. No primeiro (do tipo instrumental) foram procuradas evidências de validade de conteúdo por meio da estimação da concordância entre juízes. Nove especialistas na área de avaliação transdiagnóstica analisaram as características gerais, as problemáticas clínicas, os instrumentos propostos e as variáveis transdiagnósticas contidas no protocolo, por meio da técnica Angoff modificada. Os coeficientes $r_{\text {wg }}$ mostraram uma boa concordância entre os juízes. A análise dos índices de severidade e indulgencia indica que a avaliação dos especialistas foi favorável. No segundo estudo, o protocolo foi aplicado a 15 vítimas do conflito armado e 73 pessoas sintomáticas, e suas pontuações foram comparadas. Não houve diferenças estatisticamente significativas entre os dois grupos quanto às variáveis transdiagnósticas, esses resultados permitem inferir que o protocolo pode ser utilizado para identificar a sensitividade ansiosa, a intolerância à incerteza e o afeto positivo-negativo, como variáveis transdiagnósticas, independentemente do tipo de diagnóstico ou a condição da vítima.

Palavras-chave: Estresse, ansiedade, depressão, transdiagnóstico, protocolo.

\section{Protocolo de Evaluación Transdiagnóstico para Estrés, Ansiedad y Depresión: Un Análisis con Víctimas Colombianas}

\section{Resumen}

Siguiendo el modelo transdiagnóstico, se diseñó un protocolo de evaluación para estrés, ansiedad y depresión. Se realizaron dos estudios. El primero fue de tipo instrumental en el cual se estableció la validez de contenido del protocolo a través del juicio de armonía interjueces, con nueve expertos en evaluación transdiagnóstica, quienes evaluaron los aspectos generales, las variables transdiagnósticas incluidas, las problemáticas clínicas e instrumentos propuestos, mediante la técnica Angoff Modificada. Los coeficientes $r_{\mathrm{wg}}$ oscilaron entre .33 y .97 valores que indicaron acuerdo entre jueces. Los indicadores de severidad e indulgencia permiten inferir que la evaluación de los expertos fue favorable. En el segundo estudio se compararon las puntuaciones medias obtenidas en la aplicación del protocolo a 15 víctimas del conflicto armado y 73 personas sintomáticas. No se encontraron diferencias estadísticamente significativas entre las medias de las variables transdiagnósticas entre los dos grupos, los valores $\mathrm{p}$ oscilaron entre .09 y .95 , resultados que permiten inferir que la sensitividad ansiosa, intolerancia a la incertidumbre y afecto positivo-negativo, como variables transdiagnósticas pueden ser identificadas mediante el protocolo, independientemente del tipo de diagnóstico o condición de víctima.

Palabras clave: Estrés, ansiedad, depresión, transdiagnóstico, evaluación, protocolo.

History has shown that being exposed to fear, worry, death, conflict, and violence in general on a nearly permanent basis is an experience that produces a kind of affection or psychological or social consequence, which can be revealed in different ways. The armed conflict was con- sidered one of the highly impactful social and political events that have left the greatest number of victims, not only in Colombia but also in other countries that have suffered from it (Vallejo, 2011). According to Pérez-Sales (2010), before the negotiation and post-conflict process, more 
than two million people were displaced due to political violence and more inhabitants were displaced for economic reasons, being pushed out of the system by a breakdown of the social network or by poverty as a result of violence. From 2012, the year in which peace talks began, to 2017, when the peace agreement was signed, the armed conflict led to 218,094 documented deaths (National Center for Historical Memory, 2018).

Political violence in Colombia associated with conflicts such as guerrilla actions, drug trafficking, and paramilitary forces has shaped the history of the country since the 1960s. Given this situation, significant progress is currently being made with regard to peace negotiations with a guerrilla group (FARC-EP), which is why assistance for victims is of special interest in the post-conflict framework, particularly in truth and comprehensive reparations (Tobar, 2015).

In this regard, the work carried out with victims, specifically those related to the historical memory, has enabled the consciousness of orality and the comprehension of the origin and dynamics of stories from all parties involved in the conflict (Rueda, 2013). One topic of study is the derived psychological problem that has established that traumatic events should be analyzed within the historical context, which makes it possible to understand the transgenerational elements and diverse psychological and social responses (Borda, Carrillo, Garzón, Ramírez, \& Rodríguez, 2015).

Although studies on consequences have focused on emotional and traumatic aspects, different problems have been documented on the conflict, for example, gender violence and sexual abuse associated with displacement and insecurity (Lemaitre \& Sandvik, 2014), as well as symptoms such as paranoia, alcohol consumption, mood problems, and post-traumatic stress (Hewitt et al., 2016).

Andrade (2011) classified the mental health pathologies prevalent in 36 families displaced by the armed conflict in Colombia. The results showed the presence of mild depression $(20 \%)$, moderate depression $(60 \%$; greater among women; for every two men with depression, three women suffer this condition) and major depression (30\%). Andrade found that $100 \%$ of the population showed signs of post-traumatic major $(50 \%)$ and moderate $(40 \%)$ stress disorder. The data indicated that the psychological consequences of the conflict persist in displaced populations, constituting comorbid psychopathological cases even when the surrounding insecurity diminishes.

Restrepo, Yara, Cano, and Tavera (2014) conducted a study with a sample of 80 soldiers from the National Army of Colombia. Their objective was to establish the psychological profile of the soldiers, victims of anti-personnel landmines and improvised explosive devices by analyzing four emotional variables (depression, anxiety, anger, and stress). The results showed that anxiety-state and trait and anger-state and trait presented statistically significant differences between the groups, although no differences were found between depression and stress.

In a study conducted by Aristizábal et al. (2012), it was found that, among the psychological symptoms as a consequence of the armed conflict situation, there were psychological trauma, such as fear, distress, obsessive thoughts, compulsive acts, sadness, depression, sleep disturbance, sexual disorders, aggressive impulses, mental blocks, and psychotic episodes.

In specific populations related to victims, Ruiz (2014) mentions that, in Colombia, legal psychology has contributed to the assessment of damage associated with psychological injuries and has not been indifferent to the study of victims involved in the armed conflict. However, given the complexity of the situation, there is a need to use transdiagnostic perspectives that facilitate the identification of risk factors and protective factors associated with victimization and its prevention, the onset of disorders, as well as the reduction of effects resulting from the crimes committed.

According to Sandín, Chorot, and Valiente (2012), the transdiagnostic model, "involves understanding mental disorders on the basis of a range of causal and etiopathogenic cognitive and behavioral processes and/or processes which preserve most mental disorders or consistent 
groups of mental disorders" (p. 187), based on a dimensional perspective of the underlying processes and factors of various disorders.

The approaches to the transdiagnostic model include the contributions of traditional behaviorist schools of thought such as classical and operant conditioning to explain abnormal behavior (Skinner, 1957), personality models based on neuroticism, extraversion, and psychoticism (e.g. Eysenck, 1959), cognitive models of information processing applied to psychotherapy (e.g. Beck, 1976), and Barlow's (2002) triple vulnerability model: biological, psychological, and pathological (2002).

Subsequently, superclass transdiagnostic models have been proposed (unlike the traditional DSM-IV-TR categories) in which emotional and affective disorders are understood from a single dimensional category that includes three subclasses: anxiety-suffering (major depression, dysthymia, generalized anxiety), fear (panic, agoraphobia, social and specific phobia), and bipolar (bipolar I and II, cyclothymia; Watson, O'Hara, \& Stuart, 2008).

These models have been derived in part from Watson and Clark's proposal (1984), in which a continuum of positive and negative affect was suggested, defined in terms of response to stressors, where the general factor associated with anxiety is the negative affect understood as the temperamental sensitivity to negative stimuli that is experienced as negative emotions such as fear, anxiety, sadness, guilt, hostility, dissatisfaction, pessimism, somatic complaints, and negative self-view, while depression has been associated with low positive affect (low enthusiasm, activity, alertness, energy and low rewarding participation; Watson et al., 1988).

In light of the above, in order to develop a transdiagnostic assessment protocol (TAP), it is necessary to take into account the processes involved in the different emotional and affective disorders (Belloch, 2012). In this regard, the proposal made by Harvey, Watkins, Mansell, and Shafra (2004) presented five key domains for understanding and developing a unified intervention: attention, memory, reasoning, thinking, and behavior.
Negative affect (NA) has been defined as the temperamental sensitivity to negative stimuli that is experienced as negative emotions such as fear, anxiety, sadness, guilt, hostility, dissatisfaction, pessimism, somatic complaints, and negative self-image, while positive affect (PA) is characterized by responses such as enthusiasm, activity, alertness, energy, and rewarding participation (Watson \& Clark, 1984; Watson et al., 1988).

Intolerance of uncertainty (IU) is defined as a cognitive bias in which people negatively perceive situations they are uncertain of. It has been recognized as a variable of vulnerability due to excessive and uncontrollable concern. People with high IU usually perceive future events as highly threatening and unacceptable, and they need to reduce their possibility of occurrence through behaviors such as excessive checks, searching for guarantees, and hypervigilance (Koerner \& Dugas, 2008).

Anxiety sensitivity is defined as the fear of experiencing feelings related to anxiety (Taylor et al., 2007). It has a three-dimensional construct-somatic, social, and cognitive-related to measures of the state and characteristic of fear, anxiety, and behavioral avoidance (Kemper, Lutz, Bähr, Rüddel, \& Hock, 2012; Wilson \& Hayward, 2006).

The post-conflict framework in Colombia affects the population in general, but in particular the victims of terrorism, who are becoming even more visible as a result of the resolution of the armed conflict suffered since the 1950s, a situation that requires preparation to handle it positively.

The initial approach of a TAP should involve a step-by-step plan for the administration of psychometric instruments and other solid assessment tools, recognized by their empirical evidence, taking into account the transdiagnostic variables: positive and negative affect, intolerance to uncertainty, and anxiety sensitivity. However, it must be recognized that there are few alternatives available for assessment and, therefore, for intervention, particularly for this type of population. Therefore, this study aimed at developing a transdiagnostic assessment pro- 
tocol that enables a more precise identification of the variables common to different disorders (anxiety, depression, stress) frequent in victims, an aspect that constitutes a support tool for the subsequent intervention.

\section{Study 1}

As part of the psychometric analysis performed on the transdiagnostic assessment protocol for stress, anxiety, and depression that was designed, the content validity was established, defined as ". . . the relevance of the test's content, for the representativeness of the items that comprise it, with respect to the entirety of the field or characteristic subject to evaluation" (Álvaro, 1997, p. 190). This type of validity can be obtained through the concept of expert juries, and the more participants are involved, the more valid it will be (Carvajal, Centeno, Watson, Martínez, \& Sanz-Rubiales, 2011). "Consulting experts is the most common way to assess the quality of content, especially in educational environments, although qualitative methods based on direct observation, interviews, or document analysis are increasingly used" (Prieto \& Delgado, 2010, p. 72).

The modified Angoff technique is based on expert opinions in relation to the assessment topic analyzed. According to the literature, this method is the most widely used in various processes that involve expert opinions for psychometric procedures, enabling a consensus of the evaluations and estimating the accuracy of the indicators reviewed numerically (Ricker, 2006). Nine clinical psychologists specialized in transdiagnosis were involved, who analyzed the relevance of the transdiagnostic variables included in the protocol and the clinical problems and instruments proposed. The data was processed with the Rasch Model and the $r_{\text {wg }}$ coefficient (Benavente, 2009).

\section{Method}

Research type. This is a quantitative empirical analytic study with a non-experimental instrumental cross-sectional design (Ato, López, \& Benavente, 2013), which sought to establish the content validity of the transdiagnostic assessment protocol.

Participants. Nine clinical psychologists with a Master's degree took part in this study, all of whom were professors with more than five years of experience in undergraduate or graduate university teaching in the subjects of clinical psychology, clinical assessment, and psychotherapy.

Instruments. A form was designed for the experts 'assessment. It comprised four modules that evaluated the general aspects, transdiagnostic variables, problems, and instruments. The assessment included a scale of 1 to 10,10 being the highest rating, where each expert provided an initial grade and a final assessment. The form also included some space to add additional comments.

\section{Procedure}

Phase 1: Construction of the transdiagnostic assessment protocol following the recommendations for creating protocols in the health field.

Phase 2: Content assessment by means of inter-judge agreement among experts. The procedure implemented was the modified Angoff method. A total of nine experts met to individually evaluate all the protocol's modules, according to an assessment scale previously assigned. Grades were given individually, and then they discussed them with the other experts, and everyone explained the reasons for their score and all inconsistencies were solved in situ. After the explanations, each expert individually re-graded every element of the module.

Phase 3: With the grades given before and after the discussion, the inter-judge agreement was established, which estimates the variances between the grades obtained from each expert for every assessed module.

\section{Results}

Facets software (Linacre, 2013), which processes the information with the Rasch Model, was used for the purpose of analyzing the data 
provided by the experts (their opinion on each aspect of the protocol). This analysis provides information on the consistency of the opinions provided by the judges throughout the process and demonstrates the technical quality of the protocol. Severity/Indulgence indicates the degree of severity (high value, greater than zero) or indulgence (low value, less than zero) of each qualifier. According to Linacre (2013), values less than or equal to 2.0 are expected. Among all the data presented in Table 1, none are higher than this grade, which indicates that the assess- ments given by all the judges correspond to what is expected by the model.

The near and far adjustments establish the connection between the severity/indulgence of the qualifier and the model used (Facets Rasch). According to Linacre (2013), values less than 1,00 indicate a lack of independence of the qualifier and values greater than 1,00 show high variation in the ratings, with values acceptable when they are between 0.5 and 1.5. The assessments made by judge 3 do not match the model.

Table 1

Values Obtained by Clinical Psychologist in Experts' Judgment

\begin{tabular}{cccc}
\hline Judge & Severity/Indulgence & Near Adjustment & Far Adjustment \\
\hline 3 & .36 & $\mathbf{2 . 7 7}$ & $\mathbf{3 . 2 0}$ \\
1 & -.55 & 1.03 & .96 \\
4 & -.64 & 1.02 & 1.64 \\
5 & -.64 & .56 & .57 \\
7 & -.64 & .50 & .40 \\
2 & -.83 & .54 & .58 \\
6 & -.95 & .43 & .50 \\
8 & -1.17 & .81 & 1.25 \\
9 & -.2 .14 & .68 & $\mathbf{3 2}$ \\
\hline
\end{tabular}

Note. The indicators with mismatch are highlighted in bold. Source: Designed by the author.

The indicators of differences and agreement between the judges who evaluated the transdiagnostic assessment protocol for the stress, anxiety, and depression variables in victims and non-victims of the armed conflict are shown in Table 2.

The agreement coefficients of items 4 to 7 were less than 0.30 , which indicated low agreement. When judge 3's assessment was removed from the analysis, all the coefficients showed agreement.

Statistically significant differences were only found in item 2 , an indicator of the specific relevant objectives of the protocol. Table 2 shows the level of agreement between the judges.

\section{Study 2}

In this study, a comparison was made between the symptomatic samples and the victims of the Colombian armed conflict. It was based on the presumption of the transdiagnostic model, which highlights that there are mechanisms or processes common to different comorbid psychopathologies (Sandín et al., 2012). Therefore, transdiagnostic variables such as intolerance to uncertainty, anxiety sensitivity, and positive and negative affect were assumed as transversal variables to problems such as stress, anxiety, and depression regardless of the conditions of the victims or non-victims of the armed conflict. 
Table 2

Pre- and Post-Comparison Scores by the Experts for the 15 items Evaluated according to the WilcoxonSigned Rank Test and Pre- and Post- $r_{w g}$ Coefficients

\begin{tabular}{cccccc}
\hline Items & $\begin{array}{c}Z \text { score from Wilcox- } \\
\text { on-signed rank test }\end{array}$ & $\begin{array}{c}\text { Asymptotic sig. } \\
\text { (bilateral) }\end{array}$ & $r_{\text {wg }}$ pre & $r_{\text {wg }}$ post & $\begin{array}{c}r_{\text {wg }} \text { post without } \\
\text { judge 3 }\end{array}$ \\
\hline I1post - I1pre & $-1.638^{\mathrm{a}}$ & .101 & 0.78 & 0.85 & 0.83 \\
I2post - I2pre & $-2.388^{\mathrm{a}}$ & $\mathbf{. 0 1 7}$ & 0.61 & 0.74 & 0.72 \\
I3post - I3pre & $-1.625^{\mathrm{a}}$ & .104 & 0.67 & 0.79 & 0.79 \\
I4post - I4pre & $-1.289^{\mathrm{a}}$ & .197 & $\mathbf{0 . 1 9}$ & $\mathbf{0 . 1 9}$ & 0.83 \\
I5post - I5pre & $-1,000^{\mathrm{a}}$ & .317 & $\mathbf{0 . 2 4}$ & $\mathbf{0 . 2 3}$ & 0.79 \\
I6post - I6pre & $000^{\mathrm{b}}$ & 1.000 & $\mathbf{0 . 1 4}$ & $\mathbf{0 . 1 4}$ & 0.94 \\
I7post - I7pre & $.000^{\mathrm{b}}$ & 1.000 & $\mathbf{0 . 1 4}$ & $\mathbf{0 . 1 4}$ & 0.94 \\
I8post - I8pre & $-1.000^{\mathrm{a}}$ & .317 & $\mathbf{- 0 . 0 3}$ & $\mathbf{- 0 . 1 4}$ & 0.45 \\
I9post - I9pre & $-1.342^{\mathrm{a}}$ & .180 & 0.64 & 0.40 & 0.33 \\
I10post - I10pre & $.000^{\mathrm{b}}$ & 1.000 & 0.76 & 0.76 & 0.74 \\
I11post - I11pre & $.000^{\mathrm{b}}$ & 1.000 & 0.76 & 0.76 & 0.74 \\
I12post - I12pre & $-1.000^{\mathrm{a}}$ & .317 & 0.60 & 0.64 & 0.80 \\
I13post - I13pre & $-1.000^{\mathrm{a}}$ & .317 & 0.70 & 0.71 & 0.97 \\
I14post - I14pre & $-.447^{\mathrm{c}}$ & .655 & $\mathbf{- 0 . 1 0}$ & 0.70 & 0.94 \\
I15post - I15pre & $.000^{\mathrm{b}}$ & 1.000 & 0.70 & .70 & 0.92 \\
\hline
\end{tabular}

Notes. The indicators with mismatch are highlighted in bold.

${ }^{a}$ Based on positive ranks.

${ }^{b}$ The sum of negative ranks is equal to the sum of positive ranks.

${ }^{\mathrm{c}}$ Based on negative ranks.

Source: Designed by the author.

\section{Method}

Research type. An analytic empirical quantitative study was carried out with a non-experimental comparative cross-sectional design (Ato et al., 2013).

Participants. The sample consisted of 88 people over the age of 18 years, victims and non-victims of the armed conflict, referred by government and non-government entities, with a minimum completed level of primary education. The sample of victims $(n=15)$ was composed of six men and nine women, with an average age of 44.6 years $(S D=15.32)$, from 10 towns from which they were forcibly displaced by illegal armed groups in Colombia; $33.3 \%$ of them were identified as belonging to an armed group, $20 \%$ as community leaders, $46.7 \%$ as having survived the murder of the household's economic provider and the subsequent family disintegration, in addition to $60 \%$ who witnessed direct and indirect massacres, three of them being victims of torture $(20 \%)$, and $66.7 \%$ were subsequently expelled from their land.

The clinical reference sample was obtained by means of the cut-off points of the instruments used in the study, following the authors' recommendations regarding the estimation of the scores as suggestive of a possible pathology. The samples were distributed as follows: anxious and depressive group $(n=15$; BAI $>25$, BDI-II $>$ 20; age $A=29.6, S D=9.88$ years; $73.3 \%$ women, $26.7 \%$ men), anxious and non- depressive group $(n=22$; BAI $>25$, BDI-II $<20$, age $A=$ 
$29.14, S D=10.99$ years; $59.1 \%$ women, $40.9 \%$ men), depressive and non-anxious group $(n=13$, BDI-II $>21$, $\mathrm{BAI}<25$; age $A=28.38, S D=5.65$ years; $76.9 \%$ women, $23.1 \%$ men), stressed, non-anxious, and non-depressive group $(n=25$; PSS $>40$, BAI $<17$, BDI-II $<20$; age $A=25.36$, $S D=5.47$ years; $80 \%$ women, $20 \%$ men).

\section{Instruments}

Positive and negative affect schedule PANAS. PANAS is a questionnaire designed to evaluate the positive and negative affect as state and trait, by means of 40 items presented in a Likert form [1 (not at all or very little), 5 (extremely)]. Among the psychometric properties reported in the Spanish-language adaptation were favorable internal consistency indexes for both the positive affect ( $\alpha=.85$ and .90$)$ and negative affect $(\alpha=.81$ and .85$)$. Significant positive correlations were also reported with anxiety $(r=.32)$ and depression $(r=.55$; Robles \& Páez, 2003).

Anxiety Sensitivity Index-ASI3. This questionnaire was designed to evaluate the responses associated with the subjective and physical experience of fear-anxiety manifestations on three subscales: sensitivity to physical, cognitive, and social anxiety. It consists of 18 items, 6 for each subscale, in a Likert form [not at all or very little (0) and very much (4)]. Among its psychometric properties with Spanish samples, it showed a favorable internal consistency for each of its factors $(\alpha=.89, .90$ and .85; Sandín, Valiente, Chorot, \& Santed, 2007).

Intolerance of Uncertainty Scale - IUS. This scale was designed to evaluate the dimensions of emotional uncertainty in terms of concern or anxiety when faced with uncertainty. The IUS is composed of 27 items, each with five answer options $(1=$ Not characteristic of me at all, and $5=$ Extremely characteristic of me). Among its psychometric properties in the Spanish-language adaptation, a high coefficient of internal consistency was found $(\alpha=.91)$ and a test-retest stability $(r=.78$; González, Cubas, Rovella, \& Darías, 2006).

Perceived Stress Scale - PSS. This scale was designed to assess the level of stress per- ceived during the last month. It has a 14-item format with five-point Likert answer options (0 = never, $1=$ almost never, 2 = occasionally, 3 $=$ often, $4=$ very often). Its authors report that a direct score indicates a higher level of perceived stress, with a cut-off point of 30 . Among its properties, it showed a favorable concurrent validity with the STAI $(r=.459, p=.001)$, and an adequate internal consistency $(\alpha=.79)$ in a Chilean sample (Tapia, Cruz, Gallardo, \& Dasso, 2007).

Beck Anxiety Inventory - BAI. This inventory consists of 21 items with four response options that must be consistent with the intensity of the anxiety symptom experienced over the last week (0: not at all, 1: slightly, it does not bother me very much, 2: moderately, it was very unpleasant, but I could tolerate it, and 3: severely, I could barely tolerate it). Among its psychometric properties with Spanish samples, it showed an adequate internal consistency $(\alpha=.84)$ and a test-retest reliability $(r=.75$; Sanz, GarciaVera, \& Fortun, 2012).

Beck Depression Inventory in Spanish, Second Edition - BDI-II. This inventory contains 21 items with four options that vary according to the intensity of the depressive symptom, including sadness, crying, loss of pleasure, feelings of failure and guilt, suicidal thoughts or desires, and pessimism. The total score is obtained with a total sum that ranges between 0 and 63 points, with a cut-off point of 19. This instrument showed a high internal consistency ( $\alpha=.94$ and $\alpha=.88$ in patients previously diagnosed with major depression) in Argentine samples (Brenlla \& Rodríguez, 2006).

Procedure. The participants were invited to the study through an open and voluntary call. They were subjected to prior verification of inclusion and exclusion criteria. Afterwards, the general objective of the study was explained to them and they were asked to sign the informed consent which included the specifications of the study's ethical considerations. They were told that all questions related to the results could be sent via e-mail to the primary author of the study.

The analysis of the results was carried out using SPSS22 software, with which the cen- 
tral tendency measures obtained were average, standard deviation, and dispersion such as rank, asymmetry, and kurtosis in all the transdiagnostic and symptomatic variables. After that, normality tests were carried out by means of the Shapiro-Wilk test $(p>.05)$, recommended for samples smaller than 50 cases. Finally, differences in averages for independent samples using the Student's $t$ - test with a $95 \%$ confidence interval were checked.

\section{Results}

The victims of the armed conflict obtained high scores in the symptomatic measures of anxiety and stress $(A=19.20, S D=13.69$, and $A=$ $48, S D=11.03)$ and lower in depression $(A=$ $12.27, S D=9.24)$. In the transdiagnostic variables measured in the victims, no differences were observed in the total scores with respect to the symptomatic groups (AS: $A=21.13, S D$ $=15.37$; IU: $A=63.33, S D=25.19$; and PAN: $A=55.80, S D=7.19)$. The differences between symptomatic groups and victims of the armed conflict are shown in Table 1 for each transdiagnostic variable according to the symptomatic group.

\section{Discussion}

Evidence is obtained for the hypothesis presented in Study 2. The results achieved in the comparison tests of averages that were not statistically significant assert that the transdiagnostic variables such as IU, AS, and PAN as transversal variables to problems such as stress, anxiety, and depression are identified regardless of their conditions of part of the group of victims or nonvictims of the armed conflict.

These results favor the development of transversal and independent assessment and intervention tools for comorbid pathologies and also premorbid conditions, although there is a need to expand the study to these conditions. Thus, depressive, anxiety, and stress symptoms can be studied from the transdiagnostic variables of AS, IU, and PAN, as Talkovsky and Norton (2016) suggest that a person with high negative affect can in turn present high IU and AS, in addition to an increase in avoidance behaviors, such as complementary transdiagnostic variables that would facilitate the understanding of anxiety disorders and other pathologies (Carleton et al., 2012), a key aspect in the understanding and treatment of comorbid clinical symptoms based on the transdiagnostic model (Brown, MeiserStedman, Woods, \& Lester, 2016).

In conclusion, this study provided empirical evidence on the convergent capacity of the protocol designed to evaluate the transdiagnostic variables of AS, IU, and PAN in victims of the armed conflict and people suffering from stress, anxiety, and depression.

\section{General Discussion}

The purpose of this study was to develop and validate a transdiagnostic assessment protocol as a tool to improve the assessment processes in anxiety, stress, and depression, according to the positive and negative affect, anxiety sensitivity, and intolerance to uncertainty transdiagnostic variables. According to the results obtained, the assessment module and the sessions that comprise it show that there was a favorable agreement among the experts without significant differences, which affirms that the outlined objective was fulfilled and the protocol created can be implemented in a pilot phase.

Failure to find statistically significant differences between the symptomatic groups and victims of the conflict shows that the AS, IU, and PAN variables can be identified through the protocol regardless of the type of diagnosis or the victim's condition. It can be affirmed that the victims present a profile that resembles the clinical one, an aspect that highlights the importance of focusing intervention processes on this type of population in a transdiagnostic way.

Taking into account that the transdiagnostic model has been shown to provide more effective responses to specific disorders that show high rates of comorbidity and covariation (Belloch, 2012), each of the sessions that make up the assessment module was aimed at analyzing the individual's problem with the transdiagnostic variables of depression, anxiety, and/or stress as the baseline. 
Table 3

Test of Differences of Averages between Symptomatic Groups and Victims of the Conflict

\begin{tabular}{|c|c|c|c|c|c|c|}
\hline \multirow[t]{2}{*}{ Groups } & \multirow{2}{*}{$\begin{array}{c}\text { Transdiagnostic Variables } \\
\text { AS } \\
(M=29.14, S D=10.92)\end{array}$} & \multirow{2}{*}{$\begin{array}{c}t \\
-1.739\end{array}$} & \multirow{2}{*}{$\begin{array}{c}p \\
.095\end{array}$} & \multirow{2}{*}{$\begin{array}{c}\begin{array}{c}\text { Difference } \\
\text { of Averages }\end{array} \\
8.00\end{array}$} & \multicolumn{2}{|c|}{$\begin{array}{c}95 \% \text { Confidence Interval } \\
\text { of the Difference }\end{array}$} \\
\hline & & & & & -17.51 & 1.506 \\
\hline \multirow[t]{3}{*}{$\begin{array}{l}\text { Anxiety } \\
\text { and Victims }\end{array}$} & $\begin{array}{c}\mathrm{II} \\
(A=66.05, S D=17.18)\end{array}$ & -.363 & .720 & 2.71 & -18.17 & 12.741 \\
\hline & $\begin{array}{c}\text { APN } \\
(M=58.50, S D=9.03)\end{array}$ & -1.332 & .192 & 6.37 & -16.09 & 3.347 \\
\hline & $\begin{array}{c}\mathrm{SA} \\
(M=24.08, S D=12.10)\end{array}$ & -.311 & .758 & -1.62 & -17.51 & 1.506 \\
\hline \multirow[t]{3}{*}{$\begin{array}{l}\text { Depression } \\
\text { and Victims }\end{array}$} & $\begin{array}{c}\text { II } \\
(M=79.08, S D=19.20)\end{array}$ & -1.582 & .127 & -12.83 & -29.57 & 3.902 \\
\hline & $\begin{array}{c}\mathrm{APN} \\
(M=54.38, S D=6.34)\end{array}$ & -.380 & .707 & -1.85 & -11.87 & 8.169 \\
\hline & $\begin{array}{c}\text { SA } \\
(M=33.27, S D=15.63)\end{array}$ & -1.843 & .076 & -9.79 & -20.70 & 1,11 \\
\hline \multirow[t]{3}{*}{$\begin{array}{l}\text { Anxiety- } \\
\text { Depression } \\
\text { and Victims }\end{array}$} & $(M=66.93, S D=23.31)$ & -.061 & .952 & -.52 & -18.09 & 17.04 \\
\hline & $\begin{array}{c}\text { PAN } \\
(M=59.07, S D=8.11)\end{array}$ & -1.631 & .115 & -7.39 & -16.68 & 1.90 \\
\hline & $\begin{array}{c}\text { SA } \\
(M=15.80, S D=7.97)\end{array}$ & 1.247 & .228 & 5.33 & -3.63 & 14.29 \\
\hline \multirow[t]{2}{*}{$\begin{array}{l}\text { Stress } \\
\text { and Victims }\end{array}$} & $\begin{array}{c}\mathrm{IU} \\
(M=60.12, S D=13.83)\end{array}$ & .455 & .654 & 3.21 & $-11,57$ & 17.99 \\
\hline & $\begin{array}{c}\text { APN } \\
(M=56.60, S D=7.53)\end{array}$ & -.676 & .504 & 3.04 & -12.17 & 6.09 \\
\hline
\end{tabular}

Note. A (Average); SD (Standard Deviation); AS (Anxiety Sensitivity); IU (Intolerance to Uncertainty); PAN (Positive and Negative Affect).

Source: Designed by the author.

In this way, the protocol identifies the specific maintainers that offer therapists an alternative for the implementation of treatment adjusted to the specific needs of the individual, so that according to the data obtained in the assessment by judges, both the sessions and the transdiagnostic assessment module show an adequate level of agreement, which indicates a good structure for its subsequent assessment of the effectiveness stage.
Assuming the clinical usefulness of a transdiagnostic protocol with victims of the Colombian armed conflict will help to reduce the symptoms of anxiety and mood disorders more quickly and precisely, as reported by RomeroAcosta, Ramirez-Giraldo, Hernandez-Bustamante, and Porras-Mendoza (2017) regarding the consequences of high stress due to the presence of paramilitary groups in the Montes de María area, a place with a high level of armed 
activity at present, since these communities have been exposed to ongoing violations of human rights and international humanitarian laws such as "massacre, displacement, constriction, extortion, threats, and sexual violence" (p. 11).

On the other hand, according to Harvey et al. (2004), it can be asserted that within the transdiagnostic model are variations that seek to explain human behavior, in a limited range of behaviors with multiple causal processes; likewise, some of them relate to cognitive processes that underlie different disorders, other simple but universal processes for most behavioral problems and, finally, universal processes present for most mood disorders with or without an integrative theory. For this reason, the transdiagnostic model can include different models that would lead to varying opinions from judges, an aspect that would explain the differences found in the initial Angoff scores.

It is considered appropriate to initiate an application process for the protocol so its therapeutic efficacy can be identified, through the ecological validity and the analysis of the protocol's efficacy, in order to identify its therapeutic impact in terms of usefulness and effectiveness.

\section{Authors' Contributions}

Substantial contribution in the concept and design of the study: Bertha Lucía AvendañoPrieto, Ronald Alberto Toro Tobar, Nancy Vargas Espinosa.

Contribution to data collection: Ronald Alberto Toro Tobar.

Contribution to data analysis and interpretation: Bertha Lucía Avendaño-Prieto, Ronald Alberto Toro Tobar, Javier Villalba-Garzón.

Contribution to manuscript preparation: Bertha Lucía Avendaño-Prieto, Ronald Alberto Toro Tobar.

Contribution to critical revision, adding intelectual content: Bertha Lucía AvendañoPrieto, Ronald Alberto Toro Tobar.

\section{Conflicts of interest}

The authors declare that they have no conflict of interest related to the publication of this manuscript.

\section{References}

Álvaro, M. (1997). Psychometric principles of Psychological Assessment. In G. Buela-Casal \& J. C. Sierra (1997), Psychological Assessment Manual. Fundamentals, Techniques and Applications (pp. 173-192). Madrid: 21st Century.

Andrade, J. A. (2011). Psychopathological effects of the Colombian Armed Conflict on families in a situation of forced displacement resettled in the municipality of Cairo in 2008. Human Sciences Scientific Journal, 7(20), 111-114. Retrieved from http://www.redalyc.org/articulo. oa?id=70922149005

Aristizábal, E., Palacio, J., Madariaga, C., Osman, H., Parra, L. H, Rodríguez, J., \& López, G. (2012). Symptoms and psychic traumatism in victims and victimizers of the armed conflict in the Colombian Caribbean. Psychology in the Caribbean (Colombia), 29(1), 123-152.

Ato, M., López, J. J., \& Benavente, A. (2013). A Classification System of Research Designs in Psychology. Annals of Psychology, 29(3), 10381059. doi: 10.6018/analesps.29.3.178511

Barlow, D. H. (2002). Anxiety and its disorders: The nature and treatment of anxiety and panic $\left(2^{\text {nd }}\right.$ Ed.). New York: Guilford Press.

Beck, A. T. (1976). Cognitive therapy and the emotional disorders. New York: International Universities Press.

Belloch, A. (2012). Proposals for a transdiagnostic approach to mental and behavioral disorders: Evidence, usefulness and limitations. Journal of Psychopathology and Clinical Psychology, 17(3), 295-311.

Benavente, A. P. (2009). Measures of agreement and bias between judges (Unpublished doctoral dissertation). University of Murcia, Department of Basic Psychology and Methodology, Murcia, Spain. Retrieved from http://www.tdx.cat/bitstream/handle/10803/112752/TAPBR.pdf;jsessi onid $=5 \mathrm{D} 7372847 \mathrm{~B} 8 \mathrm{C} 766 \mathrm{D} 5 \mathrm{D} 16 \mathrm{ACE} 3447 \mathrm{BF} 0$ F2? sequence $=1$

Borda, J. P., Carrillo, J. O., Garzón, D. F., Ramírez, M. P., \& Rodríguez, N. (2015). Historical trauma. systematic review of a different approach to the armed conflict. Colombian Journal of Psychiatry, 44(1), 41-49. doi: 10.1016/j.rcp.2014.09.005 
Brenlla, M., \& Rodríguez, C. (2006). Beck BDI-II Depression Inventory Manual Argentine Adaptation. Buenos Aires: Paidós.

Brown, H. M., Meiser-Stedman, R., Woods, H., \& Lester, K. J. (2016). Cognitive vulnerabilities for depression and anxiety in childhood: Specificity of anxiety sensitivity and rumination. Behavioural and Cognitive Psychotherapy, 44(1), 30-42. doi: 10.1017/S1352465814000472

Carleton, R. N., Mulvogue, M. K., Thibodeau, M. A., McCabe, R. E., Antony, M. M., \& Asmundson, G. J. (2012). Increasingly certain about uncertainty: Intolerance of uncertainty across anxiety and depression. Journal of Anxiety Disorders, 26(3), 468-479. doi: 10.1016/j.janxdis.2012.01.011

Carvajal, A., Centeno, C., Watson, R., Martínez, M., \& Sanz-Rubiales, A. (2011). How to validate a health measurement tool. Directory of the $\mathrm{Na}$ varra Health System, 34(1), 63-72.

Eysenck, H. J. (1959). Maudsley Personality Inventory. London: University of London.

González, R. M., Cubas, L. R., Rovella, A. T., \& Darías, H. M. (2006). Spanish adaptation of the Intolerance of Uncertainty Scale: Cognitive processes, anxiety and depression. Psychology and Health, 16, 219-233.

Harvey, A. G., Watkins, E. R., Mansell, W., \& Shafran, R. (2004). Cognitive behavioral processes across psychological disorders: A transdiagnostic approach to research and treatment. Oxford, UK: Oxford University Press.

Hewitt, N., Juárez, F., Parada, A. J., Guerrero, J., Romero, Y. M., Salgado, A. M., \& Vargas, M. V. (2016). Psychological affectations, coping strategies and levels of resilience in adults exposed to the armed conflict in Colombia. Colombian Journal of Psychology, 25(1), 125-140. doi: 10.15446/rcp.v25n1.49966

Kemper, C. J., Lutz, J., Bähr, T., Rüddel, H., \& Hock, M. (2012). Construct validity of the Anxiety Sensitivity Index-3 in clinical samples. Assessment, 19(1), 89-100. doi: 10.1177/1073191111429389

Koerner, N., \& Dugas, M. J. (2008). An investigation of appraisals in individuals vulnerable to excessive worry: The role of intolerance of uncertainty. Cognitive Therapy and Research, 32(5), 619-638. doi: 10.1007/s10608-007-9125-2
Lemaitre, J., \& Sandvik, K. B. (2014). Beyond sexual violence in transitional justice: Political insecurity as a gendered harm. Feminist Legal Studies, 22(3), 243-261. doi: 10.1007/s10691-014-9274-0

Linacre, J. M. (2013). Winsteps ${ }^{\circledR}$ (Version 3.90.1) [Computer Software]. Beaverton, Oregon: Winsteps.com. Retrieved from http://www. winsteps.com/

National Center for Historical Memory. (2018). Statistics on the armed conflict in Colombia. Retrieved from http://www.centrodememoriahistorica.gov.co/micrositios/informeGeneral/estadisticas.html

Pérez-Sales, P. (2010). Identity and trauma in adolescents within the context of political violence: A psychosocial and communitarian view. Clinical Social Work Journal, 38(4), 408-417. doi: 10.1007/s10615-010-0262-9

Prieto, G., \& Delgado, A. R. (2010). Reliability and validity. Papers on Psychology, 31(1), 67-74. Retrieved from http://www.papelesdelpsicologo.es/pdf/1797.pdf

Restrepo, J. E., Yara, E. A., Cano, J., \& Tavera, L. N. (2014). Emotional profile of a group of Colombian military victims of anti-personnel landmines or improvised explosive devices. Colombian Journal of Psychiatry, 43(2), 87-95. doi: 10.1016/j.rcp.2014.02.004

Ricker, K. (2006). Setting Cut-Scores: A critical review of the Angoff and modified Angoff methods. The Alberta Journal of Educational Research, 52(1), 53-64.

Robles, R., \& Páez, F. (2003). Study on the translation into Spanish and the Psychometric Properties of the Positive and Negative Affect Schedule (PANAS). Mental Health, 26(1), 69-75.

Romero-Acosta, K., Ramirez-Giraldo, A., Hernandez-Bustamante, O., \& Porras-Mendoza, E. (2017). Mental health status of victims of the armed conflict in Chengue. Psychology of the Caribbean, 34(1), 1-20. Retrieved from http:// rcientificas.uninorte.edu.co/index.php/psicologia/article/viewFile/7691/9775

Rueda, J. F. (2013). "Reasoned Historical Memory" An inclusive proposal for victims of the internal Colombian armed conflict. Historelo. Journal on Regional and Local History, 5(10), 15-52.

Ruiz, J. I. (2014). Social Psychology and Justice. Bogotá: National University of Colombia. 
Sandín, B., Chorot, P., \& Valiente, R. M. (2012). Transdiagnosis: New frontier in clinical psychology. Journal of Psychopathology and Clinical Psychology, 17(3), 185-203.

Sandín, B., Valiente, R. M., Chorot, P., \& Santed, M. A. (2007). ASI-3: New Scale to Evaluate Anxiety Sensitivity. Journal of Psychopathology and Clinical Psychology, 12(2), 91-104. Retrieved from http://www.aepcp.net/rppc.php?id=209

Sanz, J., García-Vera, M., \& Fortun, M. (2012). The “Beck Anxiety Inventory" (BAI): Psychometric properties of the Spanish version in patients with psychological disorders Behavioral Psychology/ Psicología Conductual, 20(3), 563-583.

Skinner, B. F. (1957). Verbal behavior. Acton, MA: Copley.

Talkovsky, A. M., \& Norton, P. J. (2016). Intolerance of uncertainty and transdiagnostic group cognitive behavioral therapy for anxiety. Journal of Anxiety Disorders, 41, 108-114. doi: 10.1016/j. janxdis.2016.05.002

Tapia, D., Cruz, C., Gallardo, I., \& Dasso, M. (2007). Adaptation of the Perceived Stress Scale (PSS) in Low-Income Adult Students in Chile. Psychiatry and Mental Health, 24(1), 109-119.

Taylor, S., Zvolensky, M. J., Cox, B. J., Deacon, B., Heimberg, R. G., Ledley, D. R. ...Cárdenas, S. J. (2007). Robust dimensions of anxiety sensitivity: Development and initial validation of the Anxiety Sensitivity Index-3 (ASI-3). Psychological Assessment, 19(2), 176-188. doi: 10.1037/1040-3590.19.2.176

Tobar, J. A. (2015). Political violence and dirty war in Colombia. Report from a victim of the Colombian conflict with regard to the negotiations in Havana. Memory and Society, 19(38), 11-24. doi: 10.11144/Javeriana.mys1938.vpgs
Vallejo, G. D. (2011). Quality of life in a population displaced by the internal conflict in Colombia. Amérique Latine Histoire et Mémoire. Les Cahiers ALHIM, 21. Retrieved from http:// alhim.revues.org/3822

Watson, D., \& Clark, L. A. (1984). Negative affectivity: The disposition to experience aversive emotional states. Psychological Bulletin, 96, 465-490. doi: 10.1037/00332909.96.3.465

Watson, D., Clark, L. A., \& Tellegen, A. (1988). Cross-cultural convergence in the structure of mood: A Japanese replication and a comparison with U.S. findings. Journal of Personality and Social Psychology, 47(1), 127-144. doi: 10.1037/0022-3514.47.1.127

Watson, D., O’Hara, M. W., \& Stuart, S. (2008). Hierarchical structures of affect and psychopathology, and their implications for the classification of emotional disorders. Depression and Anxiety, 25, 282-288. doi: 10.1002/da.20496

Wilson, K. A., \& Hayward, C. (2006). Unique contributions of anxiety sensitivity to avoidance: A prospective study in adolescents. Behaviour Research and Therapy, 44(4), 601-609. doi: 10.1016/j.brat.2005.04.005

Recebido: 05/12/2016

$1^{a}$ revisión: 04/01/2018

Aceite: 05/01/2018

(cc)BY (C) The Author(s), 2018. Open Access. This article is distributed under the terms of the Creative Commons Attribution 4.0 International License (http://creativecommons.org/licenses/by/4.0/), which permits unrestricted use, distribution, and reproduction in any medium, provided you give appropriate credit to the original author(s) and the source, provide a link to the Creative Commons license, and indicate if changes were made. 